\title{
BASE NATURAL DO ORDENAMENTO JURÍDICO
}

\author{
http://dx.doi.org/10.21527/2176-6622.2019.52.62-76 \\ Recebido em: 21/2/2019 \\ Modificações requeridas em: 24/9/2019 \\ Aceito em: 25/9/2019
}

Denis Leite Rodrigues

Graduação em Direito pela Universidade da Amazônia (1995). Mestrado em Direito pela Universidade Federal do Pará (2000). Doutor em Ciencias Jurídicas y Sociales na Universidad del Museo Social Argentino - UMSA, em Buenos Aires, Argentina. Doutorando no curso de Doutorado em Direito no Programa em Pós-Graduação em Direito - PPGD - do Instituto de Ciências Jurídicas/ICJ da Universidade Federal do Pará (UFPa). Exerce atividade de magistério como professor-adjunto no curso de Direito da Universidade Federal do Pará (UFPa). http://lattes.cnpq.br/4836971452554593. denisrod@gmail.com

\section{RESUMO}

O artigo versa sobre a base natural do ordenamento jurídico, ou seja, considera o Direito natural como parte do ordenamento jurídico estatal. Busca este estudo, inicialmente, esclarecer os principais conceitos ligados à matéria, e, a partir daí, expor as considerações de diferentes correntes filosófico-jurídicas que, respectivamente, foram a fonte básica dos escritos e ensinamentos relativos ao Direito natural. Ao final, há também uma confrontação com posições doutrinárias que divergem da posição de considerar o Direito natural como parte do Direito social e efetivamente aplicado. $O$ estudo é desenvolvido por meio da análise de diversas obras doutrinárias, e dele resultam dois fatores até certo ponto opostos e paradoxais: de um lado, uma inicial tendência do crescimento do pensamento cada vez mais de natureza notada e unicamente temporal para a análise jurídica; e, de outro, a resposta fática da retomada do fundamento também divino para a construção de uma ordem jurídica (como reação, por exemplo, às guerras do século 20). A hipótese suscitada por essa análise centra-se no enfraquecimento normativo de ordens jurídicas calcadas em desconsideração ao jusnaturalismo, o que, como referido anteriormente, abriu espaço para terríveis consequências sociais. O problema básico deste estudo ora desenvolvido refere-se à necessária reafirmação de um fundamento moral ao respectivo ordenamento jurídico, algo que é intrínseco à noção de Direito natural.

Palavras-chave: Direito natural. Escolástica. Neoescolástica. Corrente moderna. Jusnaturalismo.

NATURAL BASIS OF THE LEGAL SYSTEM

\section{ABSTRACT}

The article deals with the natural basis of the legal system, that is, it considers natural law as part of the state legal system. This study initially seeks to clarify the main concepts related to the subject, and, from there, to expose the considerations of different philosophical-juridical currents that, respectively, were the basic source of writings and teachings related to natural law. In the end, there is also a confrontation with doctrinal positions that diverge from the position of considering natural law as part of social law and effectively applied. The study is developed through the analysis of several doctrinal works, and from it results two points to some extent opposite and paradoxical: on the one hand, an initial tendency of the growth of the less divine and more and more secular thought for the legal analysis; and, on the other hand, the factual response to the resumption of the divine foundation for the construction of a juridical order (as a reaction, for example, to the wars of the twentieth century). The hypothesis raised by this analysis focuses on the normative weakening of legal orders based on disregard of jusnaturalism, which, as stated above, has opened room for dire social consequences. The basic problem of this study is the necessary reaffirmation of a moral foundation to the respective legal order, something that is intrinsic in the idea of a natural law.

Keywords: Natural law. Scholastic. Neo-scholastic. Modern school. Jusnaturalism.

\section{SUMÁRIO}

1 Introdução. 2 Conceitos Básicos. 3 Correntes do Direito Natural Objeto da Presente Análise. 4 Origem do Direito Natural. 5 Noção de Lei Natural. 6 Noção de Direito Natural. 7 Posições Doutrinárias Divergentes. 8 Considerações Finais. 9 Referências. 


\section{INTRODUÇÃO}

O presente artigo tem a pretensão de expor algumas considerações acerca do Direito natural e seu enfoque no legado de pensadores ligados a basicamente três correntes representativas de seu desenvolvimento histórico, a saber: a escolástica, a nova escolástica e a moderna.

Os pensadores escolhidos para uma análise mais detida a ser empreendida são, de forma respectiva, ligados a cada uma das correntes supracitadas, quais sejam: Tomás de Aquino, Fernando Suárez e Hugo Grócio.

A primeira seção deste estudo tratará de conceitos essenciais para a noção da base natural do ordenamento jurídico. Na segunda serão expostas breves análises das correntes supracitadas, e seus elementos que as individualizam e caracterizam, de forma geral.

As seções seguintes irão expor considerações acerca do pensamento de cada um daqueles autores mencionados, relativamente à sua respectiva visão do Direito Natural, dando-se ênfase, em sequência, aos seguintes pontos: origem do Direito Natural e sua relação com uma raiz divina (seção 3); a noção de lei natural (seção 4); a ideia do Direito Natural (seção 5). A seção 6, por sua vez, mostrará algumas posições doutrinárias divergentes por parte de juristas via de regra mais recentes (quanto à valorização do Direito Natural e à consideração deste como parte efetiva de um ordenamento jurídico).

É importante frisar que os tópicos são objeto de uma extensa bibliografia, e sujeitos a diversas e valiosas posições doutrinárias. O estudo ora desenvolvido tenciona dar uma ideia geral e mais satisfatória possível sobre os assuntos ligados a seu tema, dentro das limitações de espaço inerentes a tal espécie de análise.

\section{CONCEITOS BÁSICOS}

Uma primeira terminologia a ser esclarecida é o que se deve entender por jusnaturalismo. Exprimindo ser uma tendência filosófica, este termo corresponde a um conjunto de doutrinas expressas no decorrer da História, revelando, cada uma destas, uma equivalente atitude crítica em relação ao Direito, no sentido de postular uma ordem jurídica cuja validade está assentada basicamente em uma ideia de Justiça (GARCIA MÁYNEZ, 2012). Diz-se sobre o jusnaturalismo: "Esta doctrina, desarrollada a lo largo de más de dos milenios, comprende una gran variedad de escuelas y teorías, que sostienen concepciones diferentes sobre el fundamento del derecho natural" (GREGORIO et al., 2007, p. 35).

Em contraposição ao jusnaturalismo, como uma das áreas em que se fundamenta o Direito, encontra-se o chamado juspositivismo ou positivismo jurídico. A doutrina competente, nesta seara, afirma que "a expressão 'positivismo jurídico' deriva da locução direito positivo contraposta àquela de direito natural" (BOBBIO, 2006, p. 15). Assim, justificando-se, inclusive, pelo fato de o conjunto de normas, por sua origem, ser anterior à sua sistematização filosófica, a expressão jusnaturalismo seria derivada de Direito Natural.

A distinção do que seria natural e positivo não está ligada à problemática do que seria jurídico, pois em ambos os campos repousa o Direito, mas da origem de seus ditames, uma vez que a noção de natural exprime o que é em razão de sua natureza (liga-se à ideia do grego physis), enquanto que a de positivo está assentada naquilo que é por força do que foi posto pelos homens, seja de forma legislativa ou mesmo costumeira (liga-se à terminologia grega thésis) (BOBBIO, 2006).

Será no âmbito do jusnaturalismo em que estarão assentadas as premissas doutrinárias ligadas à ideia, por exemplo, da lei natural e do Direito Natural.

Por sua vez, a lei eterna é um verdadeiro ato de império e a medida do governo de tudo que existe por parte de Deus. Tem esta norma o predicativo de eterna, pois, sendo produto da inteligência divina, está em Deus e é atemporal. A lei eterna será base de toda verdadeira lei, portanto toda norma que seja verdadeira lei será necessária derivação da lei eterna. Toda e qualquer lei será efetivamente lei na medida em que participe dos preceitos da lei eterna, e não mais o será quando desta se alijar (HERVADA, 2006).

Para se chegar a uma satisfatória compreensão do que vem a ser a lei natural, é importante uma visão prévia da lei eterna, em função de uma íntima ligação entre ambas as normas. 
Segundo Javier Hervada, inspirado na doutrina de Tomás de Aquino: "ley eterna y ley natural son dos modos distintos de ser de la misma ley. En cuanto está en Dios (sicut in regulante et mensurante) es ley eterna; en cuanto se participa en las criaturas (sicut in regulato et mensurato) es la ley natural" (HERVADA, 2006, p. 35). Continua o autor: "conocemos, pues, la ley eterna, conociendo la ley natural" (2006, p. 35). Assim sendo, de acordo com esta noção, tendo-se o conhecimento da lei natural, conhecer-se-á a lei eterna.

Há, porém, postulações diversas entre os pensadores. Para Leo Strauss, por exemplo, baseando-se na mesma concepção tomista: "a própria razão natural cria uma presunção em favor da lei divina, que completa a lei natural ou a leva à perfeição" (STRAUSS, 2014, p. 197). Por esta posição doutrinária, portanto, verifica-se ser a lei eterna (aqui chamada de lei divina) um conjunto de preceitos que traria completude à lei natural, e assim o conhecimento desta não seria elemento necessário ou determinante para o entendimento daquela.

Este estudo, neste presente pormenor, posiciona-se em favor da doutrina de Strauss, por entender que, sendo o ser humano criado à imagem e semelhança de Deus, sendo Este a totalidade e aquele uma imagem ou reflexo Deste, é claro que a lei criada por Deus é a perfeição, e a lei natural, presume-se e espera-se, irá tender à perfeição, mas com esta não coincidirá.

Quanto à lei natural, pode-se afirmar que consistiria em juízos fundamentais de ordem eminentemente moral que se manifestam em geral na consciência de ordem individual, com caráter obrigatório ou normativo (RECASENS SICHES, 1983). É importante ter em mente, neste ponto, de que "la naturaleza, base de la ley natural, no tiene aquí la acepción de naturaleza empírica causal (como complejo de hechos que se producen forzosamente), antes bien, el sentido de razón teleológica" (RECASENS SICHES, 1983, p. 370).

E é exatamente a questão teleológica, ligada à noção de razão prática, a base de outras conceituações de lei natural. Para Hervada, por exemplo, a lei natural é descrita como "el conjunto de leyes racionales que expresan el orden de las tendencias o inclinaciones naturales a los fines propios del ser humano, aquel orden que es propio del hombre como persona" (HERVADA, 2011, p. 144-145).

Deve-se atentar que, quando se trata da lei natural, faz-se referência a uma normatividade íntima ao ser humano (o que a aproxima da ordem eminentemente moral e da ideia mesma de justiça como elemento da índole de cada sujeito), enquanto que o Direito Natural será a expressão social ou comunitária desta tendência normativa inerente a cada pessoa humana (que considerará agora a Justiça no sentido de uma aplicação na vida em sociedade).

O fato, porém, é que não obstante estejam, de forma inegável, interligados, há por parte inclusive de estudiosos uma dificuldade de distinção entre lei natural e Direito Natural.

Tratando dessa problemática, Javier Hervada afirma: "la ley natural y el derecho natural - en el sentido de norma jurídica que estamos analizando - no pueden separarse, pero tampoco deben confundirse. No toda la ley natural es derecho natural" (HERVADA, 2011, p. 171). O Direito Natural, afirma Hervada "es aquella parte de la ley natural que se refiere a las relaciones de justicia; esto es, la ley natural se llama derecho natural en cuanto es regla de derecho y sólo bajo este aspecto" (p. 171). Continua Hervada: "así, los preceptos 'no matarás' y 'no hurtarás' tienen indudablemente una vertiente moral, pero son derecho natural en cuanto miran al derecho a la vida o al derecho de propiedad" (2011, p. 171). Ao final, observa Hervada: "el derecho natural es una regla natural de derecho, que regula relaciones de justicia legal, distributiva y conmutativa" (2011, p. 171).

Esclarece Carlos R. Sanz, sobre o Direito Natural clássico, que o mesmo "entiende el derecho como la mejor disposición posible, en un tiempo y en un espacio determinados, de los grupos sociales y de los hombres que los conforman y que tiene como resultado la paz social" (SANZ, 2005, p. 32).

Em um sentido geral, poder-se-ia conceituar o Direito Natural como o conjunto das normas jurídicas necessariamente resultantes da natureza humana, ou em outras palavras; o direito que, com o auxílio da razão, os seres humanos postulam em conjunto (GOMES DA SILVA, 2000).

\section{CORRENTES DO DIREITO NATURAL OBJETO DA PRESENTE ANÁLISE}

A primeira corrente do Direito Natural a ser analisada corresponde ao que historicamente foi denominado de escolástica, que data da Idade Média. 
Sobre a escolástica, afirma Woods Jr. que a terminologia foi relacionada ao pensamento desenvolvido nas universidades europeias de então, comumente chamadas de escolas. É de se notar que o termo, por outro lado, refere-se menos ao conteúdo que ao método utilizado pelos pensadores. Em regra, o método ligava-se à utilização da razão como instrumental para a dialética e estudos de Teologia e Filosofia, por meio do confronto de proposições divergentes, o qual era seguido pela solução, obtida pelo recurso à razão e autoridade. Com seu desenvolvimento, os tratados dessa corrente passaram a seguir uma pauta definida: enunciado da questão; exposição de argumentos; posição do autor e resposta às possíveis objeções (WOODS JR., 2008).

No relativo às questões jurídicas em geral, a doutrina escolástica concebe o Direito como dividido entre o Direito Natural e o Direito Positivo. Neste contexto, o Direito Positivo, como aquele conjunto de normas jurídicas postas pelos membros de uma dada sociedade, acaba por cumprir uma dupla função: de um lado, fixa os preceitos contidos nos princípios do Direito Natural para as situações concretas (porque se tais preceitos não fossem fixados em normas gerais não seriam, afinal, direito); e de outro, determina a estruturação das relações de ordem social cuja configuração foi livremente permitida pelo Direito Natural, para que os membros da respectiva coletividade pudessem livremente legislar (suas normas jurídicas de âmbito eminentemente local), dentro de um espectro de possibilidades, todas de natureza lícita, e aqui se trata do que se pode tecnicamente chamar de Direito Positivo (RECASENS SICHES, 1983).

É claro que para sua aplicação no âmbito social, mesmo as normas de Direito Natural devem se positivar, o que mesmo assim não as tornam tecnicamente Direito Positivo, no sentido aqui analisado. Como afirma um dos princípios do Direito Natural da escolástica: o Direito Natural necessita ser complementado pelo Direito Positivo, porém sempre prevalece sobre este, pois enquanto aquele é permanente este é contingente (LEVAGGI, 2004).

Com a escolástica, floresce na cultura ocidental o estudo do Direito Natural. E o principal expoente foi Tomás de Aquino, a quem é atribuída a estruturação científica dos princípios do Direito Natural clássico (LEVAGGI, 2004).

A corrente conhecida como segunda escolástica, ou neoescolástica, floresceu na Espanha entre o final do século 16 e as primeiras décadas do século 17, e foi composta por teólogos originados de várias ordens religiosas da cristandade da época. São considerados em conjunto como teólogos-juristas, porque além de versados em Teologia, foram em regra especialistas em Direito Natural. Refletindo sobre as verdades reveladas, trataram em suas obras de questões jurídicas fundamentais, tais como: o Direito em si, a Justiça, a lei natural, lei positiva, governo e poder político, entre outros relevantes temas. Pelo fato de a totalidade dos estudiosos professar o aristotelismo-tomista (com certas variações), são em conjunto considerados novos escolásticos (LEVAGGI, 2004).

Entre os pensadores destacados na neoescolástica figuram: Francisco de Vitoria, Domingo de Soto, Juan Ginés de Sepúlveda, Bartolomé de Las Casas, Fernando Vázquez de Menchaca, Luis de Molina, Gabriel Vázquez e Francisco Suárez (1548-1617). A partir da segunda metade do século 17, e durante boa parte do século 18, o Direito Natural passou a contar com uma nova corrente de pensamento, que ficou conhecida como escola moderna. Os autores desta corrente em regra escreveram doutrinas específicas sobre Direito Natural. Além disso, a partir desse momento, passou o Direito Natural a ser uma disciplina própria em universidades europeias da época. Caracteriza este contexto histórico um crescente recurso aos argumentos da razão, para, a partir do Direito Natural, buscar uma convivência mais harmoniosa e pacífica no continente europeu então marcado por guerras de fundo religioso, fruto de movimentos como a Reforma. Não por acaso, é nesse período que se dá, no âmbito científico, a substituição da Teologia pelo Direito Natural, como a ciência da vida do homem em sociedade. Quatro fatores foram determinantes para o surgimento desta corrente: as supracitadas guerras religiosas; a influência protestante; o laicismo e o racionalismo (HERVADA, 2006).

Como principais figuras do Direito Natural moderno, destacam-se: Pufendorf, Thomasio e Wolff, mas o considerado fundador foi o pensador holandês Hugo Grócio (1583-1654).

\section{ORIGEM DO DIREITO NATURAL}

Problemática filosófica típica da Idade Média nos estudos relacionados ao Direito Natural são as considerações acerca da relação deste com a vontade divina. E, como resultado de tal esforço filosófico, surgiram duas correntes distintas: o idealismo e o voluntarismo. Cada uma destas correntes visava a responder indaga- 
ções, que Welzel, citado por Gomes da Silva, exemplifica: "Encontram-se as raízes do direito em verdades racionais ou eternas ou em decisões criadoras e singulares da vontade divina? Sancionou Deus o direito porque é direito, ou é direito porque Deus o sancionou?" (GOMES DA SILVA, 2000, p. 387).

Em sua noção sobre o Direito, ao qual identifica como lei, exposta em sua obra Suma Teológica (na resposta às objeções de número 1 do artigo 1 ㅇ da questão 90 da parte I-II), Tomás de Aquino afirma: "siendo la ley una especie de regla y medida, se dice que se encuentra en algo de dos maneras" (AQUINO, 1989, p. 704). A primeira, "como en el principio mensurante y regulador. $Y$ ya que medir y regular es propio de la razón, de esta manera la ley sólo se encuentra en la razón" (p. 704). Por seu turno, a segunda, "como en lo medido y regulado. $Y$ de este modo se encuentra en todas las cosas que obedecen a alguna inclinación consiguiente a una ley" (704).

A posição de Tomás de Aquino, típica do idealismo escolástico é, em linhas gerais, exposta por John Finnis: "separar a filosofia de Tomás de Aquino de sua teologia é compatível com as distinções que ele delineia firmemente no início de suas duas sínteses teológicas maduras, a Summa contra Gentiles e a Summa Theologiae" (FINNIS, 2007, p. 28). Diz Finnis que: (i) há verdades acessíveis pela razão, e nestas incluem-se as noções de certo e errado, bem e mal; (ii) muitas de tais verdades são esclarecidas e confirmadas pela revelação divina; (iii) algumas das verdades têm seus significados somente alcançados pela reflexão teológica (FINNIS, 2007).

Afirma Javier Hervada, sobre este ponto, que a lei eterna é atribuída à "sabedoria divina, isto é, à razão divina. A lei eterna é governo divino, a lei intradivina pela qual Deus rege o universo. Não é atribuída, então, à vontade divina, mas à inteligência divina" (HERVADA, 2008, p. 392). Por sua vez, Recasens Siches, observa: "Santo Tomás enseña la existencia de una ley eterna, inmensamente rica y que regula todos los acontecimientos del universo, y de modo especial todos los actos de la historia humana" (1970, p. 35).

Por sua vez, para o voluntarismo, o Direito Natural só tem esta natureza porque Deus assim o desejou, e poderia ser de outra forma se a vontade divina assim o quisesse. Destacam-se nesta posição as figuras de Guilherme de Ockham e Duns Escoto (ou DunScot). É de se notar que a radicalização da posição do idealismo tendeu a restringir o liame de Deus com o Direito Natural (GOMES DA SILVA, 2000).

Johannes Duns Escoto foi também conhecido como Doutor Sutil. Este autor, ao tratar da metafísica aristotélica, desta se afasta em muitos pontos, postulando novos critérios para a Filosofia ocidental, critérios esses que seriam radicalizados por pensadores posteriores, a começar destacadamente com Guilherme de Ockham (SILVEIRA, 2015). Foi historicamente o primeiro pensador de vulto a metafisicamente se contrapor à escolástica.

Ao separar a teologia da metafísica, em que esta seria a ciência do ser enquanto ser, e aquela a ciência de Deus enquanto Deus, afirma Sidney Silveira que Duns Escoto, "este piedoso frade franciscano, provavelmente sem querer, deu o primeiro passo para que se cavasse um fosso entre a fé e a razão; preparou terreno, no âmbito da teoria do conhecimento, para estabelecer-se um hiato entre ser e conhecer" (SILVEIRA, 2015, p. 9-10). Escoto, dessa forma "hipertrofiou a vontade, que com ele se torna como que um ato autônomo e autodeterminado; além de abrir caminho, na perspectiva teológica, para a perda da noção de sobrenatural" (SILVEIRA, 2015, p. 10).

A posição idealista foi adotada pela neoescolástica espanhola do século 16. Defendendo a tese idealista, estes pensadores acabaram por afirmar que o Direito Natural existiria ainda que Deus não existisse. Importante atentar que a supressão de Deus na concepção da neoescolástica é de fato o argumento ad absurdum para convencer o raciocínio defendido pelos respectivos autores (GOMES DA SILVA, 2000).

Representante eminente da neoescolástica espanhola, Francisco Suárez, tratando das origens do Direito Natural, afirma: "Todas as coisas que pertencem ao direito natural provêm de Deus como autor da natureza. Ora, o principado político pertence ao direito natural. Logo, provém de Deus como autor da natureza" (2015, p. 66).

Ao tratar em sua obra sobre o poder do príncipe, Francisco Suárez afirma que este não seria originado do Direito Natural, pelo fato de o poder do príncipe não ser natural, como também porque, pelos ditames do mesmo Direito Natural, o poder de dominar as outras pessoas de uma dada comunidade não se encontra em sujeito específico, mas nesta comunidade como um todo (SUÁREZ, 2015). De fato, como afirma o autor: "esse poder espiritual não se encontra na comunidade humana enquanto algo que dela flui naturalmente" (p. 154). 
E, por se concentrar em um sujeito específico, não poderia igualmente "fundamentar-se na vontade desta mesma comunidade de ceder ou transferir a outrem esse poder, que é de ordem muito mais elevada. Portanto, não pode encontrar-se no rei pelo direito natural" (p. 154).

Para Hugo Grócio será injusto aquilo "which is repugnant to the nature of society, established among rational creatures" (GROTIUS, 1901, p. 18). Uma das concepções de Direito expostas por Grócio em sua obra diz que aquele "has the same meaning as Law, taken in its most extensive sense, to denote a rule of moral action, obliging us to do what is proper" (p. 20).

Pensador destacado na corrente do jusnaturalismo moderno, Hugo Grócio é conhecido como pai da moderna escola do Direito Natural. Embora dito por alguns juristas, como Pufendorf, que Grócio seria um renovador do Direito Natural, por supostamente ter postulado para este a independência perante a religião e determinado o instinto social do ser humano como seu fundamento exclusivo; na verdade o autor ora citado prosseguiu a tradição inaugurada pelos pensadores da neoescolástica espanhola. Para Grócio, o appetitus socialis não seria a única fonte do Direito Natural, pois o caráter social do ser humano se rege pela reta razão e esta tem Deus como sua fonte originária (GARCIA MÁYNEZ, 2012).

Destaca-se de Hugo Grócio, por exemplo, o fato de este, entre os pensadores ligados ao jusnaturalismo, ser "o primeiro que desenvolveu o argumento histórico em favor do cristianismo em sua obra De veritate religionis christianae (1627)" (CRAIG, 2012, p. 206).

Na visão de Grócio, segundo Garcia Máynez, enquanto os princípios do Direito Natural derivam da sociabilidade humana e da recta ratio, e o ser humano é parte da ordem natural, deve-se considerar a Deus com a fonte última e suprema instância daquele Direito, na medida em que a natureza é Sua obra. A noção de recta ratio, contida na definição supramencionada, foi tomada da Filosofia escolástica por Grócio. Sauter mostrou como a citada definição é uma síntese das propostas de Francisco Suárez e Gabriel Vázquez. De Vázquez, Grócio buscou os conceitos de recta ratio e de convenientia cum natura; e de Suárez, a noção de ius naturale, que o jesuíta distingue das concepções de lex naturalis e natura sociales (GARCIA MÁYNEZ, 2012).

A ligação do pensamento de Hugo Grócio com a neoescolástica espanhola revela-se em determinados pontos de seu pensamento. Por exemplo, quando ele diz que o "direito natural é aquele que teria existido, ainda que Deus não existisse", parece que, afinal, mais não é do que simples epígono da neoescolástica espanhola: formalmente, é um repetidor" (GOMES DA SILVA, 2000, p. 388). Não obstante, ao contrário do que ocorreu com a corrente espanhola, que usou este postulado como argumento ad absurdum, no caso da escola de Direito Natural, do qual fez parte Hugo Grócio, tal conjectura seria uma premissa de um sistema filosófico que levou à desvinculação do Direito Natural da Teologia (GOMES DA SILVA, 2000).

\section{NOÇÃO DE LEI NATURAL}

A primeira concepção aqui analisada é fruto da escolástica, notadamente do vulto mais célebre desta corrente, qual seja, Tomás de Aquino. Segundo a citação de Finnis, para Tomás de Aquino o termo natural refere-se ao "predicado de algo (por exemplo, uma lei ou uma virtude) apenas, quando e porque aquilo do que é predicado está conforme a razão, a razão prática ou as exigências da razoabilidade prática" (FINNIS, 2007, p. 90). Assim, uma lei será natural se esta norma estiver de acordo com os ditames da razão.

Hervada diz que "na teoria tomista, a lei natural é aquele conjunto de ditames da razão com retidão que prescrevem aquelas condutas adequadas à natureza do homem e proíbem as contrárias" (HERVADA, 2008, p. 347). Assim, "essa lei é natural porque é produto da razão natural, isto é, da razão enquanto naturalmente capta as condutas exigidas pela natureza do homem e as que são contrárias a ela" (2008, p. 347).

Sempre importante notar que ao se falar em lei natural, estar-se-á fazendo referência a uma normatividade inerente a cada ser humano individualmente, e, por isso, a uma noção muito próxima à de moral, como parte da ética (quando passa a se falar na disciplina jurídica de uma coletividade, será o caso, agora, do Direito Natural). Por isso é que a lei natural é, para Aquino, de origem divina, impressa naturalmente no ser humano por meio da participação da lei eterna (a lei divina estando na essência de Deus). Por essa razão, descreve a lei natural, vendo-a como uma participação da lei eterna na criatura com razão, isto é, no ser humano (HERVADA, 2008). 
É de se notar que ainda que Aquino creia que a visão de Deus é o fim último de todo conhecimento e esforço humano, concede ao entretenimento um espaço na vida humana. "De todos modos, estos placeres sólo se permiten en la medida en que colaboran al fin más alto o, por lo menos, no lo dificultan" (RAWLS, 1995, p. 500). Em outras palavras, há espaço para o lúdico e o lazer na vida humana.

A visão da neoescolástica espanhola será exposta a partir da análise do pensamento de um de seus maiores expoentes, qual seja, Francisco Suárez, também conhecido como Doutor Exímio.

De acordo com Del Vecchio, no tocante à Filosofia do Direito, tem grande importância o pensamento de Francisco Suárez (1548-1617), que em Tractatus de legibus ac Deo legis/atore (1612) apresentou uma das obras sistemáticas mais completas daquela disciplina. As doutrinas de Suárez sobre a lei natural ou o fundamento do poder político não possuem apenas valor histórico para o tempo em que surgiram, "mas actual, pois tratam profundamente problemas e questões que não podem deixar de ser tomados em conta por todos quantos investigam, ainda que por diferentes métodos, a essência do direito e do Estado" (DEL VECCHIO, 1979, p. 260).

Entendendo Suárez ser a lei natural a participação da lei eterna nas criaturas dotadas de razão, inicialmente questiona onde residiria a razão de ordem formal destas leis: se na própria natureza como fundamento da honestidade dos atos praticados ou na razão natural. Ele acaba por concluir que a retidão ou malícia é na verdade a base da obrigação ou da proibição contidas na lei natural. Assim, a lei natural é uma verdadeira lei na medida em que apresenta o obrigado por Deus ou o proibido por Ele, a respeito de coisas que são boas ou más, respectivamente. Para Suárez, é impossível admitir que Deus poderia não proibir o contrário à lei natural, porque, mesmo na premissa de ser a vontade de Deus livre em suas obras, Ele necessariamente teve de prescrever o bem e proibir o mal, considerando que livremente quis criar o ser humano (HERVADA, 2006).

Ainda no pensamento de Suárez, é de se destacar outros postulados, quais sejam: a lei natural, ademais de proibir um ato, pode tornar este nulo; a lei natural não admite mudança, seja ela particular ou universal, pois por ser uma propriedade da natureza racional dos seres humanos, somente se esta natureza se modificasse poder-se-ia admitir a mudança daquela; a lei natural é absolutamente indispensável por si só, e não admite mudança, seja tanto do ser humano quanto do próprio Deus (as poucas exceções à regra ou são mudança da matéria em ocasiões específicas ou seria a ação de Deus na qualidade de supremo senhor de tudo que existe); a lei natural não admite emendas ou interpretações equitativas (HERVADA, 2006).

No que tange à lei natural, portanto, a concebe Suárez "como formalmente inmutable, que no admite derogación o cambio, pero materialmente susceptible de mudanza impropia, o sea, que puede mudar la matéria misma de la ley" (LEVAGGI , 2004, p. 116). Para Suárez, ainda, a lei natural compreende a totalidade dos "preceptos o principios morales que tienen evidente honestidad, necesaria para la rectitud de las costumbres, de suerte que los opuestos contienen evidente desorden moral o malicia" (apud LEVAGGI, 2004, p. 116).

As considerações doutrinárias acerca da visão de Hugo Grócio sobre a lei natural partem do pressuposto de que ele, tendo recebido uma educação protestante, seguiu uma tendência tanto do Luteranismo como do Calvinismo, concernente ao fato de não reconhecer a lei natural como participação da lei eterna (em função de se negar uma analogia entre Deus e as criaturas). Dessa forma, estão ausentes no pensamento de Grócio considerações sobre, repita-se, ver a lei natural como participação da lei eterna e do ser humano como participação do Ser divino (HERVADA, 2006).

\section{NOÇÃO DE DIREITO NATURAL}

Aqui sendo denominada simplesmente de lei, assim conceitua Tomás de Aquino o Direito em sua obra Suma Teológica (ST I-II, q.90, a.1), citado por Finnis: "uma ordenação da razão para o bem comum de uma comunidade [completa], promulgada pela pessoa ou corpo responsável por cuidar da comunidade" (FINNIS, 2007, p. 72).

Sempre importante enfatizar que as regras que a pessoa ou a entidade responsável promulgam irão se positivar para a comunidade, ou seja, tornar-se-ão válidas e aplicáveis em determinado lugar e tempo. Na medida em que se trata de uma ordenação da razão para o benefício de uma comunidade completa, nota-se uma aproximação também com a ideia de Direito das Gentes, jus gentium, característico da noção de Direito 
Natural. O que não quer dizer que em tal contexto não possa ser incluída uma consideração de normas criadas pelo legislador para atender interesses específicos da comunidade, estando aí um enfoque ligado ao Direito Positivo.

Sobre este ponto do pensamento de Aquino, observa Hervada que o Direito ou o justo é uma obra, adequada à outra segundo certo modo de igualdade. Não obstante, uma coisa pode ser adequada ao ser humano de duas maneiras. Primeira, atendida a natureza das coisas: por exemplo, dá-se tanto para receber outro tanto; e isto é o Direito Natural. Segunda, por convenção ou acordo mútuo, quer dizer, quando alguém se diz satisfeito por receber tanto; e tal pode se dar por um acordo de vontades entre particulares ou por conveniência pública, e neste caso quando todo o povo consente em que se considera algo como adequado em ajustado a outro ou quando assim o ordena o príncipe que tem a seu cargo o cuidado com o povo e o representa. E isto é o Direito Positivo (HERVADA, 2006). Sendo direcionada ao bem comum, a lei apela às considerações da razão dos membros da respectiva comunidade, dando a estes justificativas para compreendê-lo como autoritário e obrigatório tanto moral quanto juridicamente. Mesmo nos casos em que parcelas desta comunidade prefiram um modo diverso de buscar os bens comuns, a determinação do elaborador da lei (legislador) de procurar promover estes bens não só apoia como é apoiada por sua prerrogativa de legislar. Unicamente nos casos em que estes legisladores tenham esta intenção supracitada é que estes sujeitos podem efetivamente representar o governo adequado desta comunidade (FINNIS, 2007).

A resposta à indagação sobre quais seriam os bens comuns básicos a serem perseguidos, segundo o pensamento tomista, pode ser obtida de uma análise da obra de Finnis. Segundo este autor, seriam tais bens os seguintes: a vida humana (vitahominis), um bem a ser servido e preservado; a criação e manutenção da entidade familiar, aqui envolvendo a união sexual, a procriação e a educação da respectiva descendência (coniunctio maris et feminae, et educativo liberorum, et similia); as inclinações especificamente humanas em razão dos respectivos objetos serem apreciáveis por algo que é específico ao ser humano, que é sua racionalidade (secundum naturam rationis) (FINNIS, 1998).

Esta posição tomista, no sentido de arrolar os bens comuns, é criticada por pensadores como Alasdair Macintyre. Este autor argumenta que a teoria filosófica deve questionar: Qual o bem específico para os seres humanos? Por sua vez, cada indivíduo deve se questionar: Qual o meu bem como ser humano? E enquanto nenhuma verdadeira resposta possa ser dada pelos teóricos da Filosofia que seja de uma forma ou de outra traduzível em respostas verdadeiras que possam ser dadas às suas questões práticas pelos indivíduos comuns, nenhuma resposta verdadeira pode ser dada às suas perguntas por esses indivíduos, o que não pressupõe algum tipo particular de resposta à pergunta do filósofo (MACINTYRE, 1990).

Tomás de Aquino considera que o caso central relativo à ideia de governo é aquele em que tal governo é destinado a um povo livre, e a lei aplicada a este povo possibilita uma parceria entre os sujeitos e instituições envolvidas (notadamente povo e governo). $O$ sujeito ou a entidade que possui a prerrogativa de legislar tem, igualmente, um dever de cuidar da comunidade à qual será aplicada a lei promulgada. E este cuidado inclui uma exigência imposta ao legislador para que esclareça o melhor possível o sentido da lei que fez entrar em vigência (FINNIS, 2007).

Note-se, porém, nas palavras de Finnis, que, considerando o exposto anteriormente, Tomás de Aquino considera que "fazer-se a lei pelo costume não é incompatível com esta tese; ela equivale à positivação da lei pelo povo, considerado como tendo uma autoridade e responsabilidade difusa por sua própria comunidade" (FINNIS, 2007, p. 73). Continua Finnis: "mesmo em um paraíso não contaminado por qualquer vício humano, haveria, segundo Tomás de Aquino, a necessidade de governo e lei, embora não necessariamente um governo político, ainda menos uma lei coercitiva" (2007, p. 73). Embora não deixe claro neste ponto, Tomás de Aquino, em outra parte de sua obra, afirma que a obrigação decorrente da lei deve possuir uma força coercitiva (vis coactiva) e igualmente força diretiva (vis diretiva). E isso seria a ratione legis (ST I-II, q.96, a.5), ou seja, a razão de ser da lei (FINNIS, 2007).

Na noção de Direito Natural de Aquino, relaciona-se considerações de moralidade, especificamente com a ideia de justiça. A este respeito, Farrell afirma: "Santo Tomás dice por una parte que el derecho es el objeto de la justicia y sostiene luego que la justicia es una virtud, que en ella está 'el mayor brillo de la virtud'. Se sigue de esto que el derecho es el objeto de una virtud moral" (FARRELL, 1977, p. 28). 
Fazendo uma análise geral do Direito Natural, na visão de Tomás de Aquino, o pensador Eric Voegelin afirma que para Aquino, a devida "participação na lex eterna é objetiva na medida em que não depende da iluminação individual; e confere peso à singularidade da pessoa porquanto concebe a comunidade juridicamente ordenada como o esforço cooperativo dos homines christiani livres" (VOEGELIN, 2012, p. 263). Em outras palavras; todos, como a comunidade cristã, e cada um, como filho de Deus que é; são igualmente importantes na participação na lei eterna.

Continua Voegelin, afirmando que "a teoria tomista é a solução clássica na medida em que fornece um fundamento religioso a uma ordem jurídica que respeita a estrutura ontológica da existência humana" (2012, p. 263). E esta teologia ligada a uma ordem jurídica, informa "que o mundo e o homem foram criados bons e só se tornam defeituosos em conseqüência dos atos da vontade humana" (MACINTYRE, 2001, p. 302). E estes atos da vida humana, para serem defeituosos, ou atentam de forma direta contra as normas do Direito Natural (como no caso do aplicador das leis ou do cidadão em geral); ou indiretamente, ao se criar normas de Direito Positivo que contrariam os postulados do Direito Natural (no caso do legislador).

Para Francisco Suárez, fazem parte do Direito Natural todos os preceitos "cuya obligación tenga intrínseca unión con el objeto y con la naturaleza, aunque su conocimiento necesite del discurso humano, tanto si es sencillo como si es complicado" (HERVADA, 2006, p. 70). O que, segundo Aquino, "sería derecho obtenido por conclusión - el cual tiene cierto vigor del derecho natural, pero siendo positivo - según Suárez es derecho natural" (apud HERVADA , 2006, p. 70).

Ponto destacado no pensamento de Suárez, o povo é o personagem principal da autoridade política. Todo aquele que tenha recebido de forma legítima o poder, o tem em razão de um direito tanto humano quanto político, ou seja, por consentimento popular. Segundo a doutrina de Suárez, busca-se afirmar a convicção de que a comunidade civil realiza a transferência direta do poder para a respectiva autoridade; havendo uma transferência indireta, esta efetuada por Deus. Sua posição invalida duas correntes doutrinárias sobre o poder: o contratualismo (contrato social), que na sua antropologia filosófica nega uma dimensão de ordem social para a pessoa; e a teoria do direito divino, que não considera o povo como fonte do poder. Introduzindo o povo como categoria de Direito Natural, acaba por tornar inválidas as correntes supracitadas. Curiosamente, enquanto a teoria do direito divino é contemporânea à vida e obra de Suárez, este autor se tornou um precursor das discussões contratualistas (BOEIRA, 2015).

Afirma Boeira sobre Francisco Suárez: "para ele, o povo é elemento fundamental de direito natural, sendo indispensável para a ordenação constitutiva das relações sociais e políticas" (2015, p. 37). Destaca ainda Marcos Boeira que a teoria política de Francisco Suárez "se centra basicamente na compreensão de que a raiz da autoridade civil reside naquele que detém o poder de decidir ou transferir, por direito natural, segundo sua necessidade de conservação" (p. 37).

Outro elemento importante na concepção de Francisco Suárez, considerando nesta a sinonímia de Direito com a ideia de ius, vem a ser a mudança da significação deste instituto diante da doutrina aristotélico-tomista. Segundo esta, o sentido primário de ius seria a coisa justa. Para Suárez, não obstante, muda o foco, retirando-o da coisa justa e colocando-o no direito sobre a coisa, ou seja, em um direito subjetivo (ou uma faculdade de ordem moral) sobre a coisa, prenunciando desta forma os iura naturalia como os direitos subjetivos naturais (HERVADA, 2006).

Nas palavras de Hervada, sobre a doutrina de Suárez: "puede observarse fácilmente que en Suárez la cosa justa se ha transformado en el derecho subjetivo sobre la cosa" ( 2006, p. 68). Isso é um "importante cambio que acerca a este autor a la corriente que iba perfilándose en Europa, de clara tendencia individualista, si bien él está lejos de poder ser considerado como tal" (2006, p. 68).

Citado por Bobbio, Hugo Grócio considera ser o Direito Natural um preceito da razão justa concernente a expor que uma ação será moralmente torpe ou necessária "segundo seja ou não conforme à própria natureza racional do homem, e a mostrar que tal ato é, em conseqüência disto vetado ou comandado por Deus, enquanto autor da natureza" (BOBBIO, 2006, p. 20-21). Se Deus é o autor da natureza, e um ato só será moralmente necessário e, portanto, válido se for de acordo com a natureza racional do ser humano, fica claro que o ato será comandado por Deus, pelo simples fato da conduta ter seguido os ditames Deste. 
A intenção de Grócio de fundar o Direito Natural na natureza racional do ser humano, e de fazer da sanção proveniente de Deus um ato consequente à inobservância daquelas regras (sendo esta a razão dos ditames de Direito Natural serem prescritos ou proibidos por Aquele), fez nascer a possibilidade de o racionalismo edificar uma teoria do Direito isenta de pressupostos de ordem teológica. Defende Grócio um antivoluntarismo, ao antepor a razão do ser humano à razão divina (LEVAGGI, 2004).

Sobre a doutrina de Grócio, observa-se no ser humano uma propensão a algo chamado sociabilidade (appetitus societatis), que nada mais é que um natural anseio de existir em uma comunidade organizada e pacífica. Em consequência, serão justas tanto as ações como as normas que as comandam, que aparentem ser capazes de promover uma ordenada convivência entre os seres humanos, sendo, por outro lado, condenáveis as condutas e normas que venham a turbar ou fazer impossível essa sociedade (LUMIA, 2003). Exposto aqui uma admirável concepção de Justiça, instituto objeto de discussões nos debates concernentes ao Direito Natural.

Segundo Del Vecchio, Grócio considera que "o direito é o que se mostra segundo a razão (não pela revelação) apto a tornar possível a convivência social, isto é, o que a reta razão demonstra conforme a natureza sociável do homem" (DEL VECCHIO, 2006, p. 69). E esta convivência poderia inclusive transcender os limites da pequena comunidade ou mesmo da cidade, pois cita-se na doutrina competente sobre a obra de Hugo Grócio ter este transformado a doutrina de Tomás de Aquino em relação ao Direito Natural em um verdadeiro direito entre as nações (MACINTYRE, 1991). Schneider afirma sobre Grócio: "seu projeto (De iure belli ac pacis, 1625) estava baseado na ideia de um direito natural racional, de uma ordem que o criador havia implantado no ser humano, como parte de seu equipamento racional básico" (2014, p. 547). E continua, afirmando que "isso o capacita, como membro racional, a viver numa ordem social racional e constitui a base do direito dos povos" (p. 547).

Diz Hervada, acerca de um ponto crucial da visão de Hugo Grócio sobre o Direito Natural (posição já esboçada anteriormente neste estudo), que este, em sua obra De iure belli ac pacis, adotou uma posição tanto objetivista quanto intelectualista, ao afirmar que o Direito Natural surge de princípios internos ao ser humano e é o ditame da reta razão que indica a conveniência ou não dos atos humanos relativos à sua natureza racional. Ao se adotar tal posição, o Direito Natural estará vinculado a Deus, se a razão humana for entendida como participação criada da razão divina e a lei natural como participação da lei eterna. A conclusão a que chega Grócio é que se prescindindo da teoria da participação, então o Direito Natural será concebido como algo que se origina, de forma imediata, do ser humano, e sem uma verdadeira transcendência divina o Direito Natural existiria com toda sua força mesmo que Deus não existisse. Tais postulados seriam lógicos, pois prescindir a teoria da participação supõe admitir que o Direito Natural não seria o reflexo creado de um princípio divino increado. A partir dessa premissas, era fácil chegar a um Direito Natural desvinculado de fundamentos teológicos (HERVADA, 2006).

É de se notar, porém, como já descrito anteriormente neste estudo, que as bases desta concepção de separação entre o Direito Natural e a Teologia, por meio de caminhos por vezes diversos, foram sendo construídas desde a obra de Duns Scot (contemporâneo de Tomás de Aquino), passando pela neoescolástica espanhola, até chegar ao pensamento de Hugo Grócio.

\section{POSIÇÕES DOUTRINÁRIAS DIVERGENTES}

Por certo tempo, notadamente entre os séculos 19 e 20, o jusnaturalismo e respectivos institutos conexos (como a lei natural e o Direito Natural) foram vistos como elementos a serem considerados em discussões doutrinárias, mas praticamente como tópicos ausentes dos ordenamentos jurídicos, dominados estes quase inteiramente pelo positivismo jurídico e sua aplicação normativa, qual seja, o Direito Positivo.

Assim, é possível verificar citações de alguns juristas corroborando tal consideração supra, recusando validade ao Direito Natural e o jusnaturalismo ou mesmo criticando suas várias doutrinas.

Luis Recasens Siches (em obra originalmente datada de 1958) afirma que "Derecho natural y Derecho positivo ocupan planos diversos. Al Derecho natural le corresponde la función de inspirar correctamente las normas del Derecho positivo" (RECASENS SICHES, 1983, p. 370). É uma afirmação que pode ter um sentido dúbio, uma vez que, para terem efetiva aplicação, as regras do Direito Natural devem ser aplicáveis em determinado lugar e época, portanto se positivar. A afirmação, porém, de que o Direito Natural deve inspirar as 
normas de Direito Positivo parece dizer que o primeiro não se constituiria em normas aplicáveis, e estaria ali para auxiliar o posicionamento do legislador, que criaria, aí sim, as normas jurídicas a serem uma disciplina jurídica de uma sociedade.

Em obra originalmente publicada em 1922, Roscoe Pound afirma: "o direito natural era uma teoria filosófica para um período de crescimento" (POUND, 1965, p. 21). Como se vê, este autor, de forma explícita, associa igualmente o tema desta análise unicamente com a ideia de uma postura filosófica. $\mathrm{E}$, ao usar o tempo verbal no pretérito (neste caso, imperfeito), considera as discussões sobre o assunto como algo que faria parte de um tempo que já passou.

Norberto Bobbio, comentando sobre o Direito Natural, diz ser este relativo a uma "corrente de pensamento jurídico segundo a qual uma lei, para ser lei, deve ser conforme à justiça" (BOBBIO, 2008, p. 35). Mais à frente em sua ponderação, o autor escreve: "mas se nos perguntamos o que é de fato o direito, não podemos deixar de responder que, na realidade, vale como direito também o direito injusto, e que não existe nenhum ordenamento que seja perfeitamente justo" (BOBBIO, 2008, p. 36). Esta última afirmação estará correta se se limitar à ideia de Direito Positivo. Tendo, porém, o Direito Natural como base a lei eterna, ou seja, inspiração divina, com sua absoluta correção e completude, terá aquele, como seu elemento intrínseco e característico, a Justiça. Se um Direito for injusto, ele é contrário ao Direito Natural e, portanto, não se confunde com este último. E uma noção bastante adequada de Justiça, no contexto do Direito Natural, pode se obter da doutrina de Grócio, a saber: "são justas as ações (e as normas que comandam essas ações) que pareçam idôneas a promover uma convivência ordenada entre os homens" (apud LUMIA, 2003, p. 125). E essa noção é válida em qualquer tempo e lugar.

Hans Kelsen publica em 1960, como apêndice de sua obra Teoria Pura do Direito, um texto em que se dedica a criticar em várias passagens a doutrina do jusnaturalismo e o Direito Natural como um todo. Inicialmente, ele afirma que as doutrinas de natureza jusnaturalista, da forma como foram apresentadas pelos seus mais destacados autores, "serviram principalmente para justificar as ordens jurídicas existentes e as suas instituições políticas e económicas essenciais como harmónicas com o direito natural" (KELSEN, 2009, p. 141). Não procede tal ponto de vista, posto que inclusive vultos destacados como Tomás de Aquino buscaram combater o estado de coisas então reinante na comunidade da qual fazia parte. Nesse sentido, Gilbert Keith Chesterton, em sua biografia de Aquino, afirma que assim como São Francisco, Aquino "sentiu subconscientemente que a aderência de seu povo à doutrina e disciplina católicas minguava, roídas continuamente por mais de um milênio de rotina; e que a Fé precisava ser mostrada sob nova luz e tratada desde um novo ângulo" (CHESTERTON, 2015, p. 72). Aquino, que defendia o pensamento de Aristóteles, teve, por exemplo, de encarar "o pânico acerca do perigo aristotélico, que percorrera as altas esferas da Igreja" (CHESTERTON, 2015, p. 74). Isso levando-se em consideração, ainda, que tanto a ousadia quanto a "originalidade dos pensadores do século XIII é mais surpreendente quando nos lembramos de que ocorreram sob um regime fortemente autoritário; por assim dizer, à sombra da Inquisição" (DAWSON, 2014, p. 351). Tal postura de Aquino podia ser tudo, menos a justificativa de uma ordem então reinante.

Kelsen observa que a doutrina do Direito Natural retornou a um destacado plano "da filosofia social e jurídica, acompanhada da especulação metafísico-religiosa, no século 20, como sequela das duas guerras mundiais e da reacção contra o nacional-socialismo, contra o fascismo e, especialmente, contra o comunismo" (KELSEN, 2009, p. 104-105). É de se lembrar que originalmente o comunismo era declarado como abertamente ateu, mas não é a retomada do Direito Natural uma sequela dessas guerras e ideologias, mas justamente são estas conflagrações e estes sistemas políticos que são sequelas do abandono e negação do jusnaturalismo e do Direito Natural.

Postura similar em sua crítica ao Direito Natural é a assumida por Alf Ross. Afirma este autor dinamarquês, em obra originariamente publicada em 1953, que "não é de se surpreender que o direito natural tenha voltado a prosperar em princípios do século XX e que tenha, desde então, se expandido em tal medida que é comum falar-se de um renascimento do direito natural" (ROSS , 2007, p. 296). Continua o autor: "os abalos tremendos da política e da economia que caracterizam este século têm fomentado a ânsia de descobrir algo absoluto num mundo em dissolução e mergulhado no caos" (ROSS , 2007, p. 296). Não é questão de voltar a prosperar, mas sim de que era uma temática injustamente posta praticamente no esquecimento. 
Gustav Radbruch, em obra de 1914, declara que o golpe mortal contra o chamado Direito Natural "não foi dado pela história do direito e pelo direito comparado, mas pela teoria do conhecimento; nem pela escola histórica, mas pela filosofia crítica; nem por Savigny, mas por Kant" (RADBRUCH, 2004, p. 26). Na visão de Radbruch, "a crítica da razão de Kant mostrou que a razão não é um arsenal de conhecimentos teóricos conclusos, de normas éticas e estéticas prontas para a sua aplicação, antes a faculdade de alcançar tais conhecimentos e normas" (2004, p. 26). À frente em sua obra afirma o autor que o sujeito defensor de um Direito Natural reconhecido inequivocamente deve negar a bidimensionalidade do campo jurídico e, além disso, firmar um paralelo entre o Direito Natural formal e o Direito Natural material, entre a exatidão e a vigência do Direito (p. 27). Tal defensor, para Radbruch, não é capaz de reconhecer no Direito Positivo uma razão de ser autônoma junto ao Direito Natural, "chegando a uma absorção total do direito positivo pelo direito justo, da realidade jurídica pelo valor jurídico, da ciência jurídica pela filosofia do direito" (RADBRUCH, 2004, p. 27). Para começar, como se pode constatar, é mais uma posição doutrinária que relega o Direito Natural a uma postura filosófica, negando a sua efetiva normatividade.

Ademais, ainda na análise de Radbruch, de modo algum a ideia de Direito Natural é contrária à concepção de bidimensionalidade do ordenamento jurídico.

É certo que esta postura de ver o Direito Natural negando a bidimensionalidade é típica do positivismo jurídico, pois, a partir deste, o Direito Natural passou a ser alvo de duas classes de negação: o positivismo extremado, no qual se nega a existência de uma ordem moral ou jurídica natural, que de algum modo possa condicionar o Direito Positivo; e o positivismo moderado ou objetivismo jurídico, em que não se considera o Direito Natural como parte da ordem jurídica em vigência, e sim como uma espécie de fator moral, ontológico ou axiológico (portanto, algo filosófico) que embase o ordenamento jurídico (HERVADA, 2006).

Esta concepção anteriormente descrita, como já foi referido, é produto do positivismo jurídico. É de se notar que para a ciência jurídica clássica, o Direito Natural é um tipo ou classe de Direito em vigor. É, pois, Direito e, portanto, é Direito vigente. Quando fala de direitos naturais, refere-se a verdadeiros direitos do ser humano, que são defensáveis no foro; se fala de lei natural, refere-se a preceitos, proibições e permissões de origem natural, que fazem parte do Direito vigente na sociedade. "Verdadeiros direitos e verdadeiras leis, dadas pela natureza, cuja origem última - para os teístas - se remonta a Deus" (HERVADA, 2006, p. 17).

É de se destacar que, ao comentar sobre as obras de Fernando Vázquez de Menchaca e de Hugo Grotius, afirmando ser este último pensador o iniciador da concepção imanentista do Direito Natural, entre os séculos 16 e 17, Hervada afirma que "as obras desses autores foram obras de jurisprudência, no estilo do humanismo jurídico - sem ser manuais de direito natural - nas quais o iusnaturale continuou sendo entendido como verdadeiro direito" (HERVADA, 2008, p. 24). Como se vê, a visão do Direito Natural como parte do ordenamento jurídico transcendeu o que histórica e posteriormente passou a ser considerado o Direito Natural clássico.

Em relação a este tópico, Joseph Raz, comentando sobre argumentos das teorias do Direito Natural, cita: "Todo sistema jurídico necessariamente contém ao menos algumas leis moralmente válidas e que devem, moralmente, ser seguidas" (RAZ, 2010, p. 161). Esta será, portanto, sempre uma das partes de um vigente ordenamento jurídico.

Errado é confundir um conjunto de normas jurídicas válidas e aplicáveis a uma dada coletividade em determinado tempo e lugar, ou seja, um Direito positivado, com as normas criadas por um organismo representativo de certo povo para a disciplina jurídica específica desta comunidade, criação esta que segue um procedimento legal predeterminado, aqui referido ao Direito Positivo, como aplicação prática do positivismo jurídico.

Esta problemática já foi objeto de ponderação na obra de Tomás de Aquino, como demonstra a observação de John Finnis, ao dizer que Tomás de Aquino "trata todas as leis humanas como 'positivadas' e (sinonimamente) 'positivas', mesmo aquelas regras que são reafirmações ou deduções (conclusiones) promulgadas autoritativamente a partir dos princípios ou normas morais gerais" (FINNIS, 2007, p. 733). Bem a propósito, o que seriam muitos dos direitos e garantias fundamentais, inscritos em várias Constituições nacionais desde o advento das revoluções liberais, senão normas positivadas de Direito Natural? 


\section{CONSIDERAÇÕES FINAIS}

Em 4 de agosto de 1879 o Papa Leão XIII deu um importante passo no sentido da revalorização do Direito Natural (o que se reforçaria notadamente com os eventos traumáticos do século seguinte), com a publicação da encíclica Aeterni Patris, que propunha a renovação da Filosofia tomista, com sua base eminentemente cristã, nas escolas católicas.

Destacando mais especificamente a obra de Tomás de Aquino e da corrente filosófica à qual seria filiado, Leão XIII afirma que os doutores da era medieval, que foram chamados de escolásticos, empreenderam uma imensa obra, isto é, "reunir com diligência a messe fecunda e ubertosa de doutrina espalhada nos muitíssimos volumes dos santos Padres, e, depois de a ter recolhido, puseram-na num lugar só, para uso e vantagem dos vindouros" (PECCl, 2005, p. 84). Note-se que o esforço dos filósofos, como citado, foi organizar uma obra para efetivo uso das gerações seguintes, como um conjunto de postulados para bem disciplinar a vida social. A seguir, tratando especificamente de Tomás de Aquino, o pontífice observa que aquele explorou conclusões de ordem filosófica nas razões íntimas das coisas e em princípios "universalíssimos, os quais em seu seio encerram as sementes de verdades quase infinitas, que, em tempo oportuno e com fruto abundantíssimo, seriam feitas germinar pelos futuros mestres" (PECCl, 2005, p. 86).

Noticia-se ter havido certa controvérsia em meio à comunidade católica em virtude da publicação desta Encíclica de Leão XIII. A esse respeito, argumente Alasdair Macintyre que pela metade do século 20 ou até antes, o erro de identificar a Filosofia católica com a Filosofia tomista, como Leão XIII parece ter feito em Aeterni patris, não poderia mais ser cometido. Então os questionamentos emergem: No que, caso haja, consiste a unidade da Filosofia católica? Existe algo como uma tradição filosófica católica? Se há, o que poderia ser? Definitivas e iluminadas respostas a essas questões foram dadas por João Paulo Il em sua encíclica Fides et Ratio em 1998 (MACINTYRE, 2009).

De qualquer forma, afirma-se como bastante oportuna e elogiável a iniciativa até certo ponto visionária de Leão XIII, no sentido de incentivar o renascimento dos estudos e leituras sobre o Direito Natural, ao final do século 19, entre outras razões porque, como já mencionado neste estudo, o século seguinte, com suas tragédias e vicissitudes, iria necessitar e muito desta base jurídica com inspiração divina.

A atual retomada nos estudos e análises relativos ao Direito Natural e sua aplicação às ordens jurídicas (cujos primórdios estão, entre outros pontos, na Encíclica de Leão XIII supracitada) tem como uma de suas possíveis explicações o fato da crescente redescoberta do caráter peculiar das normas de Direito Natural, no sentido de estas possuírem, em função de sua origem, além de aplicação notadamente universalista, uma inegável e profunda base moral, base esta eivada de um senso de justiça e equidade.

Clive Staples (C. S.) Lewis (que trata como lei o que seria o Direito) afirma estar consciente de haver quem afirme que a ideia de uma lei natural ou lei de dignidade relativa ao comportamento que seria do conhecimento de todos os seres humanos não teria fundamento, em razão das diversas civilizações e povos das diversas eras da civilização terem possuído doutrinas morais bastante diversas. Isso, porém, não é fato. É certo existir diferenças entre essas doutrinas morais, mas nenhuma delas chegou a apresentar algo que desse uma ideia de total diferença. Se alguém se dispuser a comparar os ensinamentos de ordem moral dos egípcios, babilônios, hindus, chineses, gregos ou romanos, ficará surpreso com o alto grau de semelhança que possuem entre si e estes com os da atualidade. "Reuni alguns desses dados concordantes no apêndice que escrevi para um outro livro" (LEWIS, 2009, p. 8-9). E neste outro livro, Lewis, no supracitado apêndice, ao qual denominou Exemplos do Tao, faz esclarecedora análise comparativa à qual se referiu. Sobre estas citações, afirmou que "os seguintes exemplos da Lei Natural são tirados de fontes que estão perfeitamente ao alcance de qualquer um que não seja historiador profissional" (LEWIS, 2012, p. 79). E, finalmente, expõe que "é no mínimo concebível que toda e qualquer civilização de que temos notícia tenha sido derivada de outra civilização e, em última análise, de um único centro - transmitida como uma doença infecciosa ou como a sucessão apostólica" (p. 80). Eis a lei natural, intrínseca à razão humana e inspirada em ideais de ordem divina.

Além disso, sendo presença e evidência da sabedoria divina na razão humana, por meio da influência da lei eterna, as normas de Direito Natural são atemporais. Esta constatação se relaciona com a ideia de eternidade. Neste pormenor, Tomás de Aquino é um dos pensadores que defende o argumento de que, se partindo 
de um ponto de vista "da eternidade (sub specieaeternitatis), toda a série de eventos temporais é real para Deus e, assim, disponível para sua influência causal em qualquer ponto da história por meio de um único ato atemporal" (MORELAND; CRAIG, 2005, p. 622).

Esse ponto foi igualmente tratado por Clive Staples (C. S.) Lewis quando este comenta, em relação a Deus: "a vida Dele não consiste em momentos que são seguidos por outros momentos" (LEWIS, 2009, p. 223). Continua o autor: "Se um milhão de pessoas oram para Ele às dez e meia da noite, Ele não precisa ouvi-las todas no instantezinho que chamamos de dez e meia" (2009, p. 223). Isso porque, afirma C. S. Lewis: "dez e meia, ou qualquer outro momento ocorrido desde a criação do mundo, é sempre o presente para Deus" (p. 223).

O caráter de universalidade e Justiça, evidenciado no Direito Natural, faz contraponto notável com o atual contexto do que se chama Direito Positivo, que corresponde às normas criadas, em regra, por um parlamento teoricamente representativo de uma dada comunidade, que, em função disso, teria condições de criar normas mais particularizadas e apropriadas àquela específica coletividade.

A realidade social destes tempos atuais, no relativo a muitas câmaras legislativas representativas, com sua corrupção endêmica, e seus lobbies e conchavos, além da usual e irracional disputa de ideais partidários e ideológicos, faz com que as normas jurídicas daí provenientes tenham cada vez menos legitimidade e representem cada vez menos os interesses reais da respectiva comunidade representada.

Para os estudiosos e artífices do Direito, "é o momento em que a voz dos juristas-filósofos se faz sentir por cima da dos juristas-intérpretes" (GOMES DA SILVA, 2000, p. 386). E tal voz afirma: "Onde antes a razão se contentava em descobrir a 'verdade' do texto jurídico, agora, a razão, insatisfeita, levanta os olhos do texto, despreza-o e procura, antes, uma 'verdade' intemporal" (GOMES DA SILVA, 2000, p. 386).

Por isso, repita-se, vem-se evidenciando a urgente necessidade de uma retomada dos estudos do jusnaturalismo e a sua aplicação crescente nas atividades administrativas, legislativas e jurisprudenciais, na forma de um efetivo Direito Natural pulsante e vigente, trazendo assim um muito maior senso de ordem e justiça, tão caro e necessário no atual contexto social da comunidade mundial.

\section{REFERÊNCIAS}

AQUINO, Santo Tomás de. Cuestione 90. Tradução ao espanhol Jesús María Rodríguez Arias. In: AQUINO, Santo Tomás de. Suma de Teología II. Parte I-II. 2. ed. Madrid, España: Biblioteca de Autores Cristianos, 1989.

BOBBıO, N. O positivismo jurídico. Lições de filosofia do direito. Tradução M. Pugliesi, E. Bini e C. E. Rodrigues. São Paulo: Ícone Editora, 2006.

BOBBIO, N. Teoria geral do direito. Tradução D. Agostinetti. 2. ed. São Paulo: Martins Fontes, 2008.

BOEIRA, M. Suárez e os problemas políticos da modernidade In: SUÁREZ, F. Defesa da fé católica. Tradução Luiz Artoga e Tiago Gadotti. Porto Alegre: Concreta, 2015.

CHESTERTON, G. K. Santo Tomás de Aquino. Tradução Antônio Emílio Angueth de Araújo. 3. ed. Campinas: Eclesiae Editora, 2015.

CRAIG, W. L. Apologética contemporânea. A veracidade da fé cristã. Tradução A. G. Mendes, H. U. Fuchs e V. Kroker. 2. ed. São Paulo: Vida Nova, 2012.

DAWSON, C. A formação da cristandade. Das origens na tradição judaico-cristã à ascensão e queda da unidade medieval. Tradução M. X. de Brito São Paulo: É Realizações, 2014.

DEL VECCHIO, G. Lições de filosofia do direito. Tradução A. J. Brandão. 5. ed. Coimbra, Portugal: Armênio Amado Editor, 1979.

DEL VECCHIO, G. História da filosofia do direito. Tradução J. B. da Silva. Belo Horizonte: Editora Líder, 2006.

FARRELL, M. D. Cuestiones de filosofía y derecho. Buenos Aires: Cooperadora de Derecho y Ciencias Sociales, 1977.

FINNIS, J. Aquinas. Moral, political and legal theory. New York, United States: Oxford University Press, 1998.

FINNIS, J. Direito natural em Tomás de Aquino. Sua reinserção no contexto do juspositivismo analítico. Tradução L. Cordioli. Porto Alegre: Sergio Antonio Fabris, 2007.

GARCIA MÁYNEZ, E. La definición del derecho. Ensayo de perspectivismo jurídico. México D. F.: Ediciones Coyoacán, 2012.

GOMES DA SILVA, N. J. E. História do direito português. Fontes de direito. 3. ed. Lisboa, Portugal: Fundação Calouste Gulbenkian, 2000.

GREGORIO, J. C. de et. al. Teoria del derecho. Madrid, España: Uned, 2007. 
GROTIUS, Hugo. The rights of war and peace. Tradução ao inglês de A. C. Campbell, A. M. Washington, United States: M. Walter Dunne Publisher, 1901.

HERVADA, J. Síntesis de historia de la ciencia del derecho natural. Pamplona, España: Ediciones Universidad de Navarra, 2006. HERVADA, J. Lições propedêuticas de filosofia do direito Tradução E. M. Gasparotto. São Paulo: WMF Martins Fontes, 2008. HERVADA, J. Introducción crítica al derecho natural. 11. ed. Pamplona, España: Ediciones Universidad de Navarra, 2011. KELSEN, H. A justiça e o direito natural. Tradução J. B. Machado. Coimbra, Portugal: Almedina, 2009.

LEVAGGI, Abelardo. Manual de historia del derecho argentino. Castellano - Indiano/Nacional. 3. ed. Buenos Aires: Depalma, 2004.

LEWIS, C. S. Cristianismo puro e simples. Tradução Á. Oppermann e M. B. Cipolla. 3. ed. São Paulo: WMF Martins Fontes, 2009. LEWIS, C. S. A abolição do homem. Tradução R. Mannarino Filho. 2. ed. São Paulo: WMF Martins Fontes, 2012.

LUMIA, G. Elementos de teoria e ideologia do direito. Tradução D. Agostinetti. São Paulo: Martins Fontes, 2003.

MACINTYRE, A. Three rival versions of moral enquiry. Encyclopaedia, genealogy and tradition.1. ed. Indiana, United States: University of Notre Dame Press, 1990.

MACINTYRE, A. Historia de la ética. Tradução ao espanhol R. J. Walton. Barcelona, España: Ediciones Paidos, 1991.

MACINTYRE, A. Depois da virtude. Um estudo em teoria moral. Tradução J. Simões. Bauru: Edusc, 2001.

MACINTYRE, A. God, philosophy, universities. A selective history of the catholic philosophical tradition. 1. ed. Maryland, USA: Rowman \& Littlefield Publishers, 2009.

MORELAND, J. P.; CRAIG, W. L. Filosofia e cosmovisão cristã. Tradução E. Justino, H. Heim, L. Aranha, R. Portella e S. da S. Saraiva. São Paulo: Vida Nova, 2005.

PECCI, G. V. Aeterni patris. A renovação da filosofia cristã tomista nas escolas católicas. In: PECCl, G. V. Documentos de Leão XIII (1878-1903). Tradução H. Dalbosco e L. Costa. São Paulo: Paulus, 2005. (Coleção Documentos da Igreja).

POUND, R. Introdução à filosofia do direito. Tradução Á. Cabral. Rio de Janeiro: Zahar Editores, 1965.

RADBRUCH, G. Filosofia do direito. Tradução M. Holzhausen. São Paulo: Martins Fontes, 2004.

RAWLS, J. Teoría de la justicia. Tradução para o espanhol M. D. González. 2. ed. México D. F. México: Fondo de Cultura Económica, 1995.

RAZ, J. Razão prática e normas. Tradução J. G. Ghirardi. Rio de Janeiro: Elsevier, 2010.

RECASENS SICHES, L. IUs naturalismos actuales comparados. Madrid, España: Universidad de Madrid; Facultad de Derecho; Seccion de Publicaciones e Intercambio, 1970.

RECASENS SICHES, L. Tratado general de filosofía del derecho. 8. ed. México D. F., México: Editorial Porrua, 1983.

ROSS, A. Direito e justiça. Trad. Edson Bini. Bauru: Edipro, 2007.

SANZ, C. R. La respuesta del derecho natural clásico a los desafíos del siglo XXI. In: FRONTERA, C. et. al. La codificación: raíces y prospectiva. ¿Qué derecho, qué códigos, qué enseñanza? 1. ed. Buenos Aires: Universitas, 2005.

SCHNEIDER, H. Protestantismo. In: KAUFMANN, T.; KOTTJE, R. et. al. História ecumênica da igreja 2. Da alta Idade Média até o início da Idade Moderna. Tradução I. J. Rabuske. São Paulo: Edições Loyola; Paulus; São Leopoldo: Editora Sinodal, 2014.

SILVEIRA, S. Duns Scot, filósofo da ruptura. In: SCOT, Duns. Tratado do primeiro princípio. Tradução C. Nougué. São Paulo: É Realizações, 2015.

STRAUSS, L. Direito natural e história. Tradução B. C. Simões. São Paulo: Editora WMF Martins Fontes, 2014.

SUÁREZ, F. Defesa da fé católica. Tradução L. Artoga e T. Gadotti. Porto Alegre: Concreta, 2015.

VOEGELIN, E. Idade média até Tomás de Aquino. História das ideias políticas. Tradução M. C. Henriques. São Paulo: É Realizações, 2012.

WOODS JR., T. E. Como a igreja católica construiu a civilização ocidental. Tradução E. Carillo. 2. ed. São Paulo: Quadrante, 2008. 